\title{
HEAT ABSORPTION IN FLUID USING INDUCTION HEATING TECHNOLOGY
}

\author{
Tushar M. Patil ${ }^{1}$, Umesh S. Bhadade ${ }^{2}$ \\ ${ }^{1}$ Electronics \& Telecommunication Dept, S.S.B.T.. College of Engineering, Bambhori, \\ Jalgaon-425002, Maharashtra, India \\ ${ }^{2}$ Information Technology Dept, S.S.B.T.. College of Engineering, Bambhori, Jalgaon- \\ 425002, Maharashtra, India.
}

\begin{abstract}
Induction heating $(I H)$ is a technique of heating electrically conducting materials by the application of electromagnetic induction. The heat generated in the object using eddy current itself in the object, instead of by an external heat source via heat conduction. This technique obeys contactless heating. Using this technique objects can be heated very rapidly. Ferromagnetic material and its alloys like iron, stainless steel responds best to induction heating. This technique has good efficiency up to 94\%. This technique is in practice at industries for annealing, brazing, welding, melting of metals. Due to the large evolution in technology this technique became much popular food processing at day to day life.

In the present study, IH technology successfully introduces to heat liquid materials like water, oil, etc. Two types of load coils are prepared 1) Mild steel and 2) Stainless steel material, respectively. The objective is to investigate the amount of heat absorption generated using IH into the fluid flowing through the load coil. It is observed that the amount of heat is $80 \mathrm{C}$ to $120 \mathrm{C}$ more than the conventional systems.
\end{abstract}

\section{KEYWORDS:}

Eddy current, Fluid, Heating, Induction

\section{INTRODUCTION}

Hot water has various applications, such as bathing, washing, equipment sterilization, cooking, and many more activities. Some special applications in industries require hot oil baths for various processes. It is also observed that ready-to-eat food also needs to heat in food processing industries. Mostly, such type of heating is achieved using immersion heating or using liquid petroleum gas (LPG) technique. Improved efficiency along with minimum power consumption is the need of today's world. But immersion heaters have less efficiency $(59 \%$ to $74 \%)[1,2]$. Also, these applications have the risk of hazard, due to the leakage of the immersion coil [3]. It requires more time for immersion heating technique and the user has to wait for hot fluid (water or oil). LPG geysers cause pollution and may be dangerous if the LPG flow becomes faulty. Such a system leads to gas leakage, due to the aging of the gas flowing pipe, especially in industries where chemical processes occur continuously. Due to carbon monoxide emission, such systems are also called slow killer systems [4]. The efficiency of the LPG system is up to 70\% [2].

The IH technique has attained considerable growth in its original system. Today, this technology has become very comfortable in controlling the power. The IH principle has been employed in DOI: 10.14810/elelij.2019.8201 
industries for several years to heat numerous magnetic materials. Sometimes, it is also included in the process of melting metals [7]. Taking these factors into account; the employment of the IH principle for fluid heating appears practical.

The paper is organized as follows: Section "I" provides the overall operating principle of the IH. Section "II" presents a description of practical setup and the procedure used to carry out the experiment. This section also depicts design for various load coils. Various results and discussions on the same is carried out in the last section. Here, practical observations are noted, and the parameters, such as temperature, power, cost, safety, efficiency, emission and time, and so on.

\section{Section I}

\section{IH SYSTEM}

The IH technique is well known as a contactless heating technique. The technique is divided into three major aspects: a) electromagnetic coil in combination with the b) driver circuit and c) microcontroller based controlling unit. The user can program the circuit to achieve the desired temperature using the controlling unit. The electromagnetic waves generated by the IH system can link only with magnetic materials. Hence, the user has to apply this principle only for magnetic materials such as iron, steel, nickel, manganese, cobalt, and so on.Fig.1 demonstrates the operating principle of an IH system. When the inductor (IH coil) is energized, it develops the alternating flux around the IH coil [ $8 \& 12]$. The strength of the flux depends on the frequency and the power applied to the IH coil. The alternating flux induces eddy currents in the target, i.e., the metallic piece shown in Fig. 1. As the load is a solid magnetic material, the eddy currents induced in it get short-circuited. This process develops heat in the target using Joule's effect. According technology target is heated by means of two physical phenomena: eddy currents and magnetic hysteresis [8-13].

This phenomenon is the main heating source in the IH process. In addition to this, magnetic hysteresis creates an additional heating component in ferromagnetic materials. The typical operating frequency of these systems ranges from line frequency to few $\mathrm{MHz}$, and the operating voltage ranges from several volts to several thousands of volts.

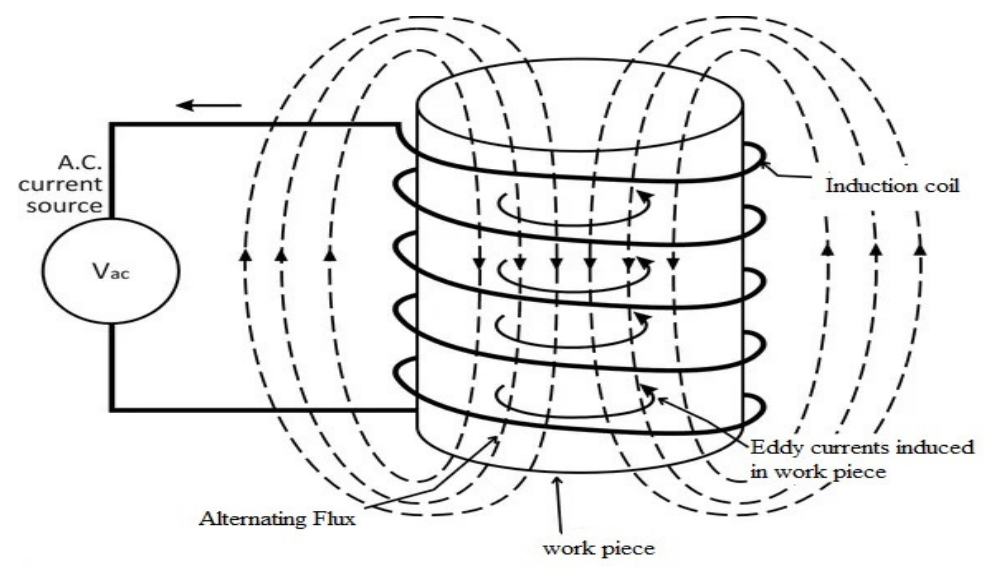

Fig. 1 Working Principle of Induction Heating 


\section{Section II}

\section{EXPERIMENTAl SETUP AND Methodology}

The application is founded on a 4-bit microcontroller. The power manipulation capacity is $2000 \mathrm{~W}$, with a supply voltage of $230 \mathrm{v} / 50 \mathrm{~Hz}$ AC. The induction generating coil is made up of multi-strand copper lead technology. Fig. 2 illustrates the interfacing diagram of the experiment.

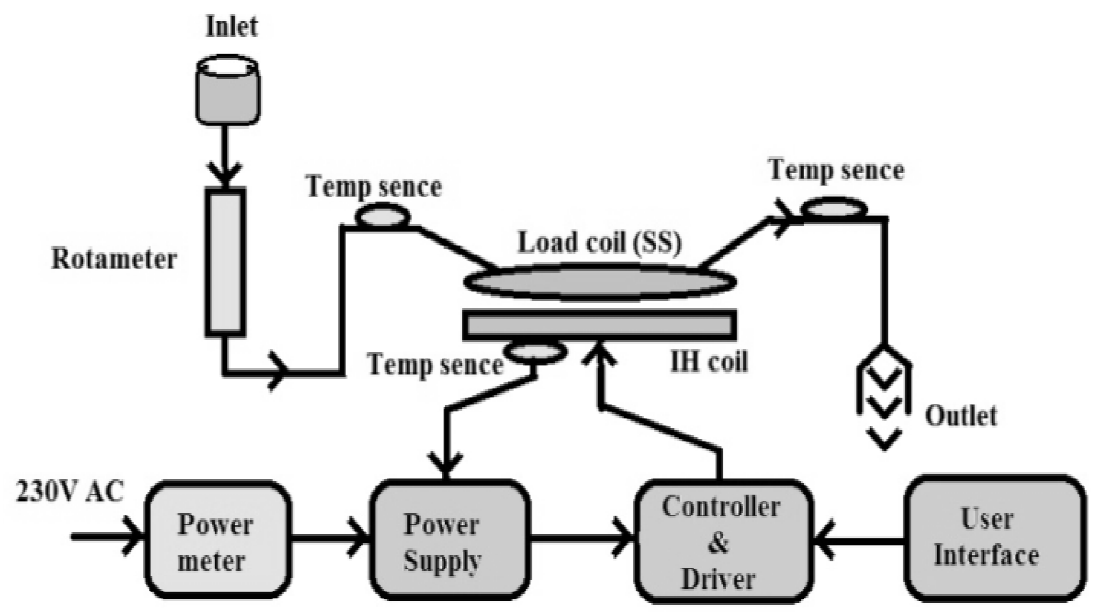

Fig. 2 Block Schematic of a System

The IH coil has 45 turns of 30 copper strands to handle maximum power. The thickness of each strand is 32 AWG. The arrangement of IH coil and load coil is modified as per the requisite for easy handling and better operation. In addition, the Rotameter is inserted in the inlet terminal to control the flow of liquid and the temperature meter to monitor the temperature in degree centigrade. To measure the power consumption throughout the experiment, the digital display panel power meter is also wired with the circuit [5-7, 11-19].

To obtain maximum efficiency, two segments of load coils are designed. Fig. 3 shows the experimental load coil construction for the same. The first coil is made up of mild steel (MS) material. The $8 \mathrm{~mm}$ hollow MS pipe is spirally twisted as shown in the diagram. Each turn is neatly welded with MS material to form an electrically closed loop so that maximum EMF will be short-circuited in the coil. The MS pipe has a length of 11.5' (3.35 meters). The outer diameter of the complete coil is around 9 inches. 

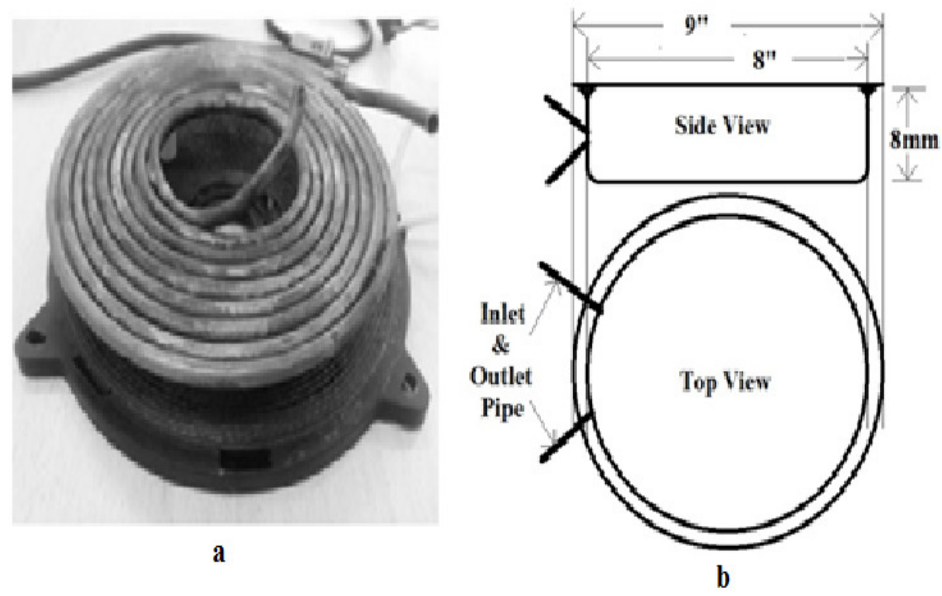

Fig. 3 Construction of Load Coils

The second load coil is made up of stainless steel (SS) material. Both surfaces are welded at the ends only. The load has a circular shape with an inner diameter of 8 inches, and the separation of both surfaces is $10 \mathrm{~mm}$ internally, with the thickness of the plate being $1 \mathrm{~mm}$.

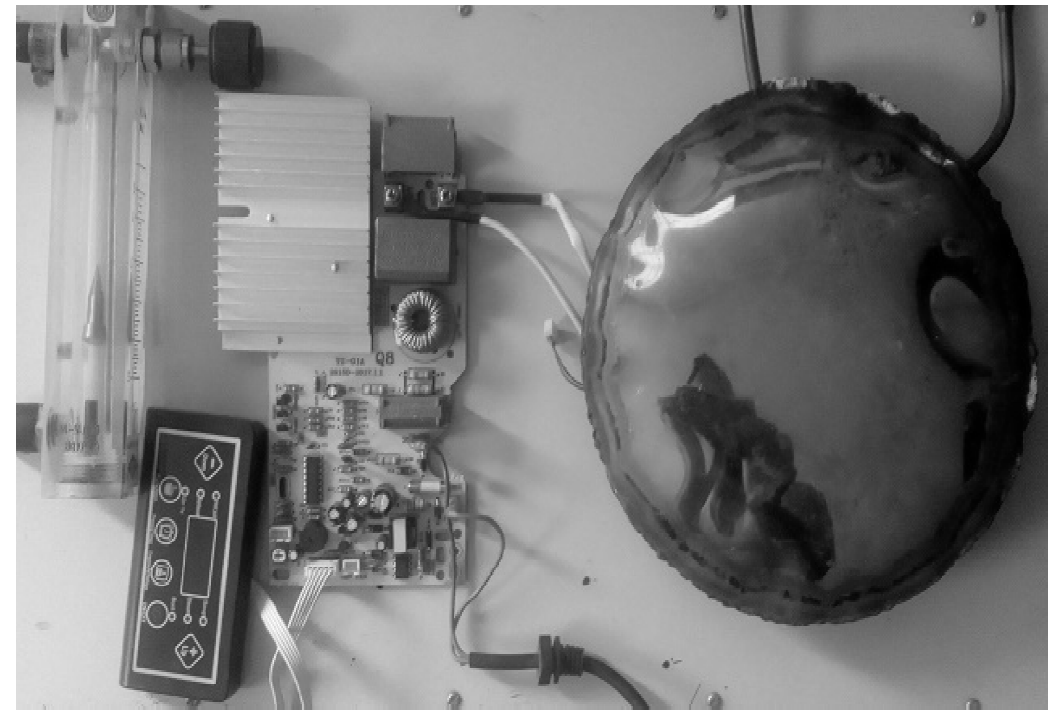

Fig.4 Practical Setup using SS load

Heat absorption, also known as heat transfer or heat exchange, is an endothermic process described by the second law of thermodynamics. The law states that thermal energy transitions from a hotter mass to a cooler mass to reach thermodynamic equilibrium. Once both objects reach thermodynamic equilibrium or the same temperatures, the heat transfer between the two objects will equal zero. Heat is conducted in the metals from a hot object towards the cold object. Longer an object is exposed to a heat source; the more heat will be absorbed. Different substances have different capacities for absorbing heat $[25,26]$. For both methods; the procedure to measure temperature is the same. The water flow variations in the steps, with the help of the Rotameter, 
and simultaneously, the input and output temperature is noted. Fig. 4 shows the practical setup of the IH-based geyser with the SS load coil.

\section{Section III}

\section{RESULTS AND DisCUSSION}

Power is constant at $1300 \mathrm{~W}$. Here, the measurement of the total rise in temperature is observed with respect to the water flow. For example, the total rise in temperature is $30^{\circ} \mathrm{C}$ when the flow of water is $1 \mathrm{LPM}$.

Table 1 shows the observations for the MS and SS load coil. It also shows the observations for the immersion geyser technique. Power is kept constant at $1.3 \mathrm{KW}$. For $1 \mathrm{LPM}$ flow of water, the total rise in temperature is $30^{\circ} \mathrm{C}$ for the SS load coil, whereas it is $29^{\circ} \mathrm{C}$ for the MS load coil. The total increase in temperature is from $0.8^{\circ} \mathrm{C}$ to $1.8^{\circ} \mathrm{C}$ in the $\mathrm{SS}$ coil rather than the MS coil.

Nowadays, immersion geysers are popular. The observations for the immersion geyser are made with reference to the system developed by Jamie Bristol, which attempts to achieve a total rise in temperature. To observe the behavior of the system again, the same power is considered. As the volume of fluid increases, the required power in Watts also rises to achieve the same temperature. The time and power required to heat the same quantity of water using this method are also noted [20-24].

Table 1. Rise in temperature for IH and Immersion Technique.

\begin{tabular}{|c|c|c|c|c|c|c|c|}
\hline $\begin{array}{l}\text { LP } \\
\text { M }\end{array}$ & $\begin{array}{l}\text { Rise in } \\
\text { Temperatur } \\
\text { e }\left({ }^{0} \mathrm{C}\right) \mathrm{M} \text {. } \\
\text { S. Coil }(\mathrm{X})\end{array}$ & $\begin{array}{l}\text { Rise in } \\
\text { Temperatur } \\
\text { e }\left({ }^{0} \mathrm{C}\right) \text { S.S. } \\
\text { Coil }\end{array}$ & $\begin{array}{l}\text { Rise in } \\
\text { temperatur } \\
\mathrm{e}\left({ }^{0} \mathrm{C}\right) \\
\text { Immersion } \\
\text { Geyser }\end{array}$ & $\begin{array}{l}\text { Time } \\
\text { for IH } \\
\text { in } \\
\text { second } \\
\mathrm{s}\end{array}$ & $\begin{array}{l}\text { Powe } \\
\mathrm{r} \text { for } \\
\text { IH } \\
\text { (Watt } \\
\text { ) }\end{array}$ & $\begin{array}{l}\text { Power } \\
\text { needed to } \\
\text { heat } 60 \mathrm{Sec} . \\
\text { for } \\
\text { immersion } \\
\text { geyser } \\
\text { (Watt) }\end{array}$ & $\begin{array}{l}\text { Time to } \\
\text { reach for } \\
\text { Immersio } \\
\mathrm{n} \text { geyser } \\
\text { in second }\end{array}$ \\
\hline 0.3 & 40 & NA & NA & \multirow{15}{*}{60} & \multirow{15}{*}{1300} & NA & $\mathrm{NA}$ \\
\hline 0.5 & 36 & 36.4 & 37 & & & 1330 & 64 \\
\hline 0.7 & 34 & NA & NA & & & NA & NA \\
\hline 0.75 & NA & 34.9 & 25 & & & 1840 & 84.72 \\
\hline 1 & 29 & 30 & 19 & & & 2180 & 100 \\
\hline 1.2 & 25 & NA & $\mathrm{NA}$ & & & NA & NA \\
\hline 1.25 & NA & 25.8 & 15 & & & 2260 & 104.1 \\
\hline 1.5 & NA & 24.6 & 12.5 & & & 2590 & 119.1 \\
\hline 1.75 & NA & 23.8 & 10.6 & & & 2920 & 133.29 \\
\hline 2 & 19 & 19.3 & 9.3 & & & 2780 & 122.6 \\
\hline 2.25 & NA & 18.5 & 8.3 & & & 2920 & 134.4 \\
\hline 2.5 & NA & 17.8 & 7.45 & & & 3100 & 143.6 \\
\hline 2.75 & NA & 16.4 & 6.75 & & & 3170 & 145.6 \\
\hline 3 & 13 & 13.8 & 6.2 & & & 2740 & 125.8 \\
\hline 4 & 6 & NA & NA & & & 1680 & 77.46 \\
\hline
\end{tabular}


The first column indicates the flow of water in LPM. The second column shows the total rise in temperature for the MS load coil and the next column defines the total rise in temperature for the SS load coil. The fourth column indicates the observations for the immersion geyser. The time and power to heat the water are kept constant at $60 \mathrm{Sec}$ and $1300 \mathrm{~W}$, respectively, which is noted in the next two columns. It is observed that the lower temperature is absorbed by the fluid in the immersion geyser. To consider the issues regarding efficiency calculations, the observation of temperature, required time and power requirement for the immersion geyser system is to be measured. The second last column shows the power in Watts when the time is kept constant at 60Sec. Additionally, the last column depicts the time in seconds required to achieve the same temperature as per the SS load of the IH system, when the power is kept constant at $1300 \mathrm{~W}$ for the immersion geyser.

\subsection{LPM Vs Total Rise in Temperature}

The graphical analysis exhibits a total increase in temperature of the respective flow of water in LPM. Initially, for the low flow rate $(0.5 \mathrm{LPM})$, the total rise in temperature is about the same with only a 2-degree centigrade difference. However, as the flow rate increases, the IH technology provides better results and also provides a considerable increase in temperature.

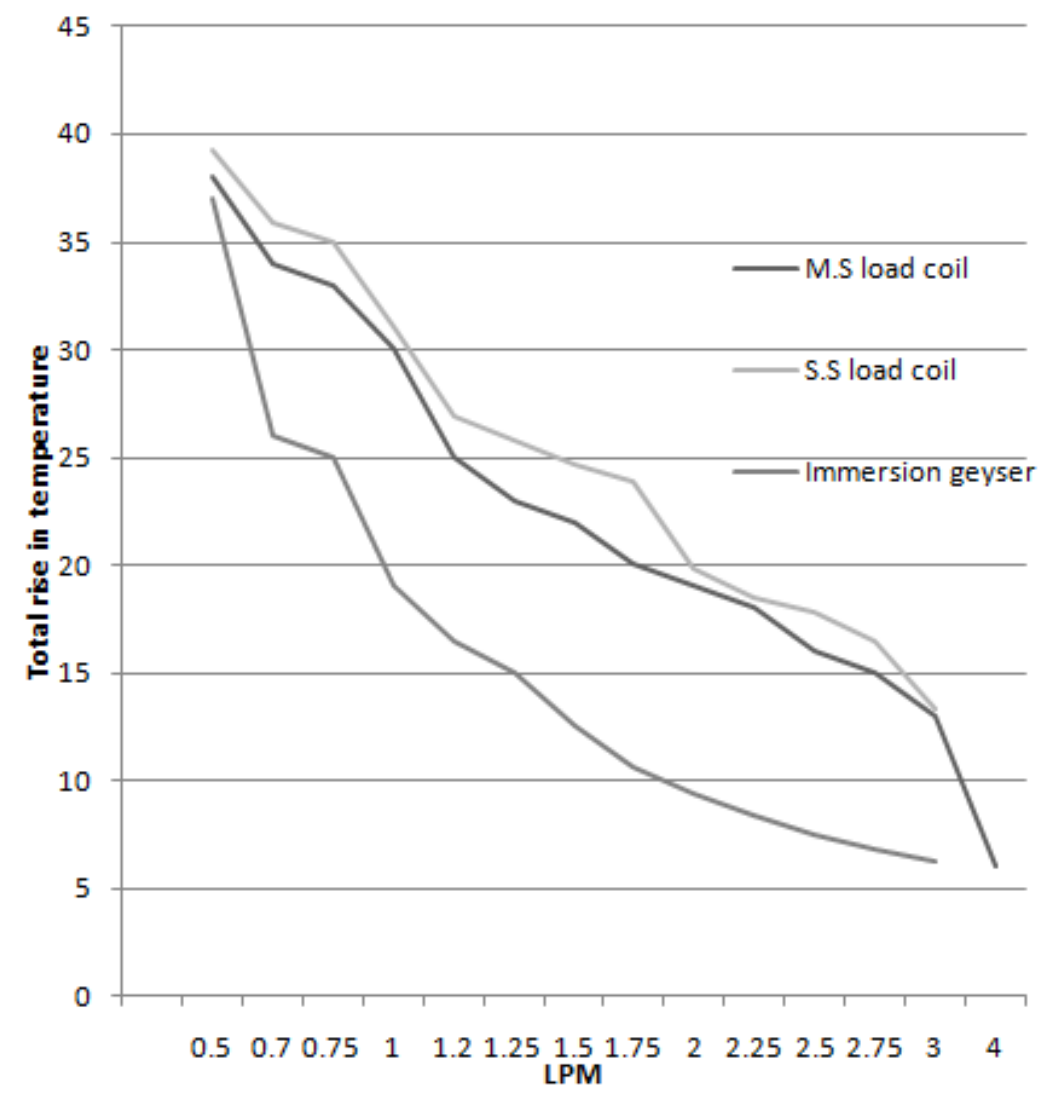

Fig. 5 Plot between Flow Rate and Rise in Temperature from Aforementioned Observations 
The plot of the IH technology has an almost straight line, while such behavior does not occur in immersion geyser technology. One thing that is observed again is that the temperature gain of the SS coil is highest among all others.

\subsection{Heat Absorption}

A material such as SS absorbs more heat and transfers it to the fluid, as compared to MS material. In terms of the immersion geyser, the filament gets heated first, and then the surrounding metal tube is heated. The electrical insulator is placed between the filament and outer tube. Due to the fact that indirect heat is induced in the outer coil, the heat absorption appears less as compare to $\mathrm{IH}$. Also, in terms of the Gas geyser, the heat is produced at the burner. This heat is absorbed by the metal fins, and again, it's absorbed by the copper tubing, and then, it is transferred to the liquid flowing through it. As direct heat is not transferred to the copper coil, the heat absorption is much lesser than in the LPG technique as well as in the immersion geyser also.

From Table 1, it is noted that up to the flow of $2.5 \mathrm{LPM}$, the IH system performs excellently. After the value of $2.5 \mathrm{LPM}$, the ratio decreases but is still considered good.

\subsection{Power Requirements}

The power required in IH is considerably low. In terms of the immersion geyser, the power loss is due to the high resistance of the coil, so it isn't able to induce more temperature as in the case of the IH [1]. If LPG geysers are taken into account, the required volume of gas is more as compared to the aforementioned methods [1-3]. Fig. 6 shows the plot of power and the rise in temperature, where it is observed that there is the constant line at $1300 \mathrm{~W}$ for the IH system. The immersion technique needs more power if requires the same temperature in the same time that is required for the IH technique. When power is kept constant, it is observed that the temperature gain is more in $\mathrm{IH}$, with respect to immersion technology. The average increase in temperature is $6^{0} \mathrm{C}$ to $8^{0} \mathrm{C}$. The temperature in an LPG-operated geyser can be increased by increasing the gas flow, which is more expensive than in IH $[2,5]$.

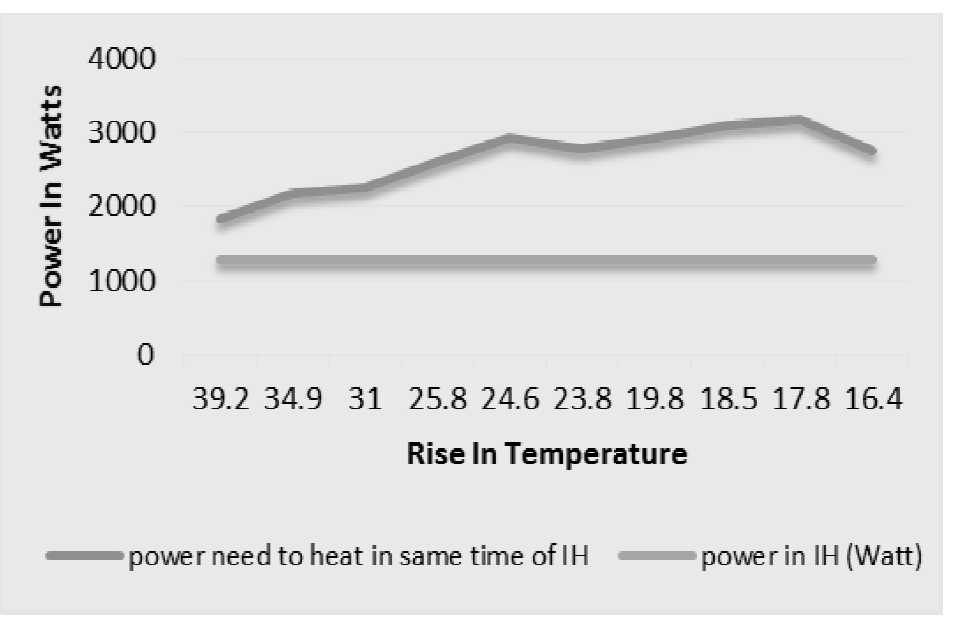

Fig. 6 Plot between Rise in Temperature and Power Required 


\subsection{Efficiency}

According to the research conducted by the energy-ex of non-conventional power devices Pvt. Ltd. Panaji, Goa, India, the parameters of various devices are a) efficiency, b) time required to boil 2 liters of water and c) power applied. The observation clearly shows that the IH system provides better efficiency than any other method that depends on either gas or electricity.

Table 2. Efficiency chart for various methods.

\begin{tabular}{|l|l|l|l|l|}
\hline Type & Efficiency & Time & Energy & Power \\
\hline $\begin{array}{l}\text { Induction } \\
\text { stove }\end{array}$ & $90 \%$ & 4 minutes & $745 \mathrm{KJ} / \mathrm{s}$ & $3.1 \mathrm{KW}$ \\
\hline $\begin{array}{l}\text { Electric } \\
\text { Coil }\end{array}$ & $55 \%$ & 9 minutes & $\begin{array}{l}1220 \\
\mathrm{KJ} / \mathrm{s}\end{array}$ & $2.3 \mathrm{KW}$ \\
\hline Gas & $40 \%$ & 8 minutes & $1700 \mathrm{KJ} / \mathrm{s}$ & $3.54 \mathrm{KW}$ \\
\hline & & & & \\
\hline
\end{tabular}

The results given above are the open pot applications for the IH system. Here, the efficiency ranges from $88 \%$ to $94 \%$ for the water flow from 0.5 LMP to 4 LPM.

\subsection{Emission}

Compared to nature-friendly equipment, the immersion geyser and IH geyser have no emission. But, the same is not considerable in the case of an LPG geyser, due to the burning of fossil fuels. Sometimes, in atmospheric conditions, these geysers emit more smoke. In such cases, suffocation takes place if ventilation is not maintained properly.

\subsection{Safety}

The manner in which your system will become more eco-friendly and safe, one cannot neglect the possibility of an electric shock for immersion geyser, because the heating coil is fitted around the metal tube with an insulator. In working conditions, these tubes may go bust and the coil may directly come into contact with the fluid, which may cause an electric shock. An LPG geyser has a pipe with gas flowing through made up of rubber. After a periodic interval, it gets damaged and simultaneously, if the ignition process in the geyser is occurring, then in such situations, a fire hazard may take place. In industries where it this occurs in large amounts, the hazard may become a serious case. In contrast, IH technology is contactless heating technology. The associated fluid does not come in contact with the electric circuitry and it also does not emit explosive gases. Hence, there is no possibility of a hazard and it is completely safe.

\subsection{Time required}

By taking into account all the aforementioned results, it is implied that the total time required to heat the fluid using IH technique is less as compared to earlier methods.

\subsection{Power loss}

Table2 in terms of fuel conversion implies that the power loss in an LPG gas geyser is $60 \%$, whereas, in the immersion geyser, it is closer to $26 \%$. Furthermore, in case of the IH method, the 
total power loss is in between $6 \%$ to $12 \%$. This is the minimum figure as compared to traditional methods.

\subsection{Cost}

By considering today's market trends, the cost of any system must satisfy all its required constraints. The cost for an LPG gas geyser is within the range of Rs. $3000=00$ to $6500=00$ in Indian Rupees, whereas the immersion geyser costs within the range of Rs. $3500=00$ to $7000=00$. In accordance with available equipment, the IH geyser will be priced from Rs. $3000=00$ to $5000=00$. For large volume applications, the cost of the IH technique will be less as compared to other techniques.

\section{Conclusion}

It is observed that the average temperature increases from $6^{0} \mathrm{C}$ to $8^{0} \mathrm{C}$ in $\mathrm{IH}$ technology as compared to immersion heating technology, whereas the same increases from $0.8^{0} \mathrm{C}$ to $1.2^{0} \mathrm{C}$ in the SS load coil as compared to MS load coil. In the case of the flow ranging from 0.5 LPM to 4 $\mathrm{LPM}$, the rise in temperature is from $36.4^{0} \mathrm{C}$ to $13.8^{\circ} \mathrm{C}$ using $\mathrm{IH}$ technology. From the history and the current observations based on $\mathrm{IH}$, it is seen that it has delivered better efficiency. In the figure, it falls within the range of $88 \%$ to $92 \%$, which is $17 \%$ to $25 \%$ more than in traditional methods. The system has a power loss ranging from about $8 \%$ to $12 \%$. Hence, the IH technique for a geyser can be a better power saving application than the immersion geyser technique and obviously the LPG technique. This application can be adopted for geysers in bathrooms, kitchens, hospitals, restaurants and in many more places where the instant hot fluid is required. This may also apply to heat slurries of various ready-to-eat preparations, hot oil baths, and so on.

\section{REFERENCES}

[1] Lucía, O., Maussion, P., Dede, E. J., \& Burdío, J. M. (2014). Induction heating technology and its applications: Past developments, current technology, and future challenges. IEEE transactions on Industrial electronics, 61(5), 2509.

[2] Non Conventional Power Devices Pvt. Ltd. Energy excess, A-9 Neugi Nagar, Portais, Panji Goa 403001, India.

[3] Chen, X., Liu, Y., Qin, H., Zhang, L., Zhu, H., Yang, Y., Guan, P. (2015). Death due to electrocution during shower, one case report and brief review of the literature. 163163-166. doi: $10.4323 /$ rjlm.2015.

[4] Chong, C K., Senan, P., Kumar, G. V., \& Pejabat Kesihatan Cameron Highlands (1997). Carbon monoxide poisoning from gas water heater installed and operated in the bathroom. Med J Malaysia, 52(2), 169-171.

[5] Patil, T. M., \&Bhadade, U. S.(2015). Induction Heating as fluid geyser, International Conference on Industrial Instrumentation and Control, College of Engineering Pune, India, 28-30 May 2015. pp. $170-174$.

[6] Kouzaev, G. A. (2013).Applications of advanced electromagnetics components and systems. Heidelberg, New York, Dordrecht, London: Springer. ISBN 978-3-642-30309-8.

[7] Patil, T. M., \& Bhadade, U. S. (2017). Analysis of Modified Load Coil for IH Geyser, IEEE TENSYMP 2017, IEEE Region 10 Symposium, Le-meridian, Cochin, India, 14-16 July 2017. 
Electrical and Electronics Engineering: An International Journal (ELELIJ) Vol.8, No.2, May 2019

[8] Zinn, S., \&Lee Semiatin, P. (1988).Elements of induction heating: Design, control, and applications. ASM International. doi: 10.1361/eoih1988p001

[9] Mühlbauer, A. (2008). History of induction heating and melting. Essen, Germany: Vulkan-Verlag.

[10] Kulkarni, S. V., \& Khaperde, S. A. (2005).Transformer engineering design \& practice. Marcel Dekker, Inc. ISBN: 0-8247-5653-3.

[11] Rudnev, V., Loveless, D., Cook, R., \& Black, M. (2003). Handbook of induction heating. New York, NY: Marcel Dekker.

[12] Mithal, G. K., \&Gupta, M. (2013).Industrial and Power Electronics. Khanna Publication. ISBN: 817409-109-2.

[13] Fujimoto, M. (2007). Physics of Classical Electromagnetism. New York, NY: Springer Science\& Business Media, LLC. ISBN: 978-0-387-68015-6.

[14] Maguire, J., Fang, X., \& Eric Wilson National Renewable Energy Laboratory (2013).Comparison of advanced residential water heating technologies in the United States.22-23. NREL/TP-5500-55475.

[15] Fitzpatrick, R. Maxwell's equations and the principles of electromagnetism. Massachusetts, New Delhi: Infinity Science Press LLC. ISBN: 978-1-934015-20-9.

[16] Kouzaev, G. A. Applications of advanced electromagnetics components and systems. Heidelberg, New York, Dordrecht, London: Springer. doi: 10.1007/978-3-642-30310-4.

[17] Plonsey, R., \&Collin, R. E. (1961).Principals and applications of Electromagnetic Fields.US: McGraw-Hill Book Company, Inc. 78910 - M P. - 987.

[18] Pan, L., Lui, D., \& Lun, T. C. Designing an Induction cooker (Freescale Semiconductor, Inc. Application Note AN5030, Rev. 11/2014).

[19] Moorthi, V. R. (2005). Power electronics devices, circuits, and industrial applications. Oxford University Press. ISBN-13:978-0-19-567092-9.

[20] Sarnago, H., Lucía, O., Mediano, A., \&Burdío, J. M. (2013). High efficiency parallel quasi-resonant current source inverter featuring SiC OSFETs for induction heating systems with coupled inductors.IET power electron, 1,183-191.

[21] Rathod, M. M. (2014). Heat Mass Transfer(3rd ed.). New Delhi, India. ISBN 8131806138.

[22] Haimbaugh, R. E.Practical induction heat treating. Ohio, USA: ASM International, 2001-1-93401520-9, Massachusetts, New Delhi: Infinity Science Press LLC.

[23] Bristall, J., Process heating services, Noddington Ave, Whittington, Lichfield WS14 9NQ, United Kingdom.

[24] Patoux, J. (2008). Cooking inductively: ADII coupler technology isolates the hob and the user interface. Analog devices, 42.

[25] Powell, R. W., Ho, C. Y., \& Liley, P. E. (1966). Thermal conductivity of selected materials.US: U.S. Department of commerce, National Bureau of Standards.

[26] Elert, G. (Ed.), “"Resistivity of steel", The Physics Fact book. Retrieved andarchived16 June 2011.

[27] Serway, R. A. (1998).Principles of physics(2nd ed.). Fort Worth, Texas, London: Saunders College Pub.602.ISBN0-03-020457-7. 